\title{
História a partir das coisas: tendências recentes nos estudos de cultura material
}

\author{
Marcelo Rede \\ Departamento de História, Instituto de Ciências \\ Humanas e Filosofia/Universidade Federal \\ Fluminense
}

\section{Steven Lubar \& W. David Kingery (Ed.) History from things: essays on material culture. Washington: Smithsonian Institution Press, 1993.}

Duas questões devem fazer parte do repertório de preocupações dos historiadores que se interessam pela cultura material. A primeira diz respeito à constituição mesma das sociedades estudadas, particularmente ao papel dos "segmentos do universo físico culturalmente apropriado" na trajetória dos agrupamentos humanos. Tratando-se de uma perspectiva histórica, os problemas levantados e as respostas encontradas deverão variar em grau não menor, de sociedade para sociedade ou de época para época, do que aqueles que dizem respeito, digamos, às formas de produção ou aos modos de pensar. Ainda que, como sucede em outros campos, postulados gerais sejam admissiveis (por exemplo, a mediação da cultura material na adaptação ecológica e sociocultural das populações), o mais importante e característico para o historiador serão as variações, as formas cambiantes de interação entre as sociedades e sua cultura material. Por outro lado, por se tratar de um saber obtido por métodos e estratégias de análise peculiares, a segunda preocupação localizar-se-á, irremediavelmente, na operação que insere a cultura material no processo historiográfico de produção do conhecimento. Quais os potenciais e os limites da cultura material para propor e resolver problemas históricos? Quais as particularidades e forçosas adaptações metodológicas requeridas pela mobilização desse tipo de fonte? Que lugar a cultura material ocupa no espectro 
de fontes utilizadas e como se dá a sua articulação? Em suma, como fazer da cultura material documento e quais as implicaçōes disso para a historiografia?

As duas preocupações são suficientemente extensas para abrigar muitos outros problemas importantes. Por isso podem servir de eixo encaminhador para uma reflexão sobre o assunto, sobretudo porque derivam do caráter duplo das relações entre os pólos em questão, sendo a cultura material, a um só tempo, parte do fenômeno histórico e fonte documental para sua compreensão.

Em abril de 1989, sob os auspícios da Smithsonian Institution, vários especialistas reuniram-se para debater a problemática da história e da cultura material, em um congresso nomeado History from things: the use of objects in understanding the past. Muitas das contribuições foram publicadas posteriormente, em 1993, sob o fítulo History from things: essays on material culture. Os artigos apresentam poșturas variadas e apontam para encaminhamentos muitas vezes contraditórios. É uma diversidade que deve ser considerada enriquecedora, mais do que esterelizante. Por outro lado, é possível notar aí um tratamento particular de certas questões que marcam os estudos de cultura material que, nas últimas duas décadas, têm proliferado nos Estados Unidos, sem que a coletânea possa ser tomada, portanto, como índice de tendências gerais.

A intenção é avaliar a posição dos autores face às duas questões enunciadas acima, apontando suas aproximações e distanciamentos, sem buscar, entretanto, um mapeamento exaustivo do campo lque, aliás, seria altamente desejável, mas excede aos propósitos deste ensaio).

Um aspecto dessa tradição norte-americana - que já se adianta, aqui, como um dado importante de seu enquadramento institucional - é sua concentração em esferas exteriores à História. É o que se reproduz na coletânea em foco. Em sua maioria, os autores não são historiadores: oito são antropólogos e arqueólogos (dois ramos muito ligados no ambiente norte-americano); três, incluindo os dois organizadores, estão associados a áreas tecnológicas no estudo das Humanidades; outros setores, com um representante cada, são Psicologia; Geografia; Folclore; Museus. Os dois historiadores participantes provêm de áreas específicas, como a História da Arte e da Tecnologia, em que a penetração da cultura material, de modo variável, mostra já um longo retrospecto.

Para o historiador, essa situação apresenta-se como uma possibilidade de aproveitamento interdisciplinar e, ao mesmo tempo, como um alerta para a necessidade de formular embasamentos teórico-metodológicos que se ajustem às suas perspectivas epistemológicas. Uma definição histórica dos problemas da cultura material e sua inserção adequada nos procedimentos heurísticos da historiografia não são, como se verá, pontos resolvidos nem desafios pequenos.

Nas duas partes a seguir, serão discutidas, respectivamente, as visōes sobre a relação entre a cultura e os segmentos materiais culturalmente apropriados (e suas implicações para o conceito de cultura materiall) e as posições acerca do tratamento documental da cultura material.

\section{As sociedades humanas e os segmentos materiais culturalmente apropriados}

A expressão cultura material é polissêmica e pode dar margem a 
como uma forma de conhecimento (implicando uma proposta de método etc.). A ambigüidade atravessa os dois níveis de sentido ao deixar implícita a oposição a uma pretensa cultura imaterial. No que diz respeito à definição de cultura, veremos adiante que o binômio material/imaterial é fonte de sérios problemas. Inicialmente, no entanto, apenas frisemos que a formulação dos diversos conceitos de cultura material está sempre intimamente ligada à visão que os autores têm da própria noção de cultura; por assim dizer, corresponde-the organicamente. Ao mesmo tempo, as posições sobre as relações entre o universo material e a cultura definirão, de algum modo, os limites das propostas de estudo e as formas de mobilização dos elementos físicos na compreensão dos fenômenos históricos.

A cultura e o universo mental

Para iniciar a consideração do problema, vejamos as afirmações de Jules D. Prown, historiador da arte de Yale, que dão ressonância a idéias muito divulgadas. Prown ("The truth of material culture: history or fiction", p. 1-19) apresenta a cultura material como um conjunto de "manifestations of culture through material productions". Mais adiante, completa, esclarecendo suas bases teóricas: "The underlying premise is that human-made objects reflect, consciously or unconsciously, directly or indirectly, the beliefs of the individuals who commissioned, fabricated, purchased, or used them and, by extension, the beliefs of the larger society to which these individuals belonged" (p. 1).

Salientem-se os dois ingredientes centrais da definição: o divórcio entre um âmbito geral da cultura e uma de suas manifestações, de natureza física, que é apresentada como um seu reflexo; e, em segundo lugar, a importância conferida ao indivíduo como foco de observação, sem que se leve em conta que a transição do indivíduo para a sociedade não é apenas um problema de escala.

O fundamento da primeira idéia é conhecido: as diversas abordagens que, concebendo um núcleo matricial, localizam na sua periferia objetos que, não tendo substância própria, dependem das transferências de atributos a partir do núcleo para compor sua identidade. O centro seria, então, o verdadeiro gerador das realidades. Um exemplo são as diferentes teorias do reflexo, que, na história da arte, fizeram dos objetos artísticos exalações reflexivas de configurações civilizacionais, de espírito de época (Zeitgeist), de infra-estruturas econômicas etc., etc.

No artigo de Prown, a cultura é definida sobretudo por atributos ideacionais (crenças; valores; idéias; postulados). A cultura material seria, portanto, reflexo de uma cultura concebida como patrimônio abstrato, alheia a toda materialidade. Assim sendo, a sua mobilização analítica esclareceria prioritariamente o universo mental da sociedade. Daí o sentido da analogia sugerida por Prown (p.4) entre os artefatos e os sonhos: numa perspectiva freudiana, os sonhos são ficções que demonstram a capacidade humana de exprimir, de trazer à tona, os conteúdos desapercebidos da vida quotidiana. Similarmente, tratar os objetos como ficções, mais do que como histórias, permitiria vếlos, além de suas funções intencionais, como portadores de "unconscious representations of hidden mind" e, pois, reveladores de uma "deeper cultural truth". 
A conseqüência que mais nos interessa salientar nesse tipo de argumentação é o esvaziamento da historicidade da noção de cultura. Prow: desvincula de quase toda especificidade espaço-temporal as crenças expressa: pelos artefatos; para ele "the most persistent metaphors in objects (...) relate to such fundamental human experiences as mortality and death; love, sexuality, and gender roles; privacy (seeing and being seen) and communication; power or control and acceptance; fear and danger; and, as here, giving and receiving" (p. 11). É escusado lembrar que, para cada uma dessas "experiências humanas fundamentais", existe vasta literatura a mostrar a sua historicidade.

Outros autores chegam a posições semelhantes por vias diferentes. Em seu artigo ("Objects as instruments, objects as signs", p. 30-40), Jacques Maquet, reprocessando a abordagem semiológica, inicia por considerar os sentidos como qualidades atribuídas aos objetos pelo consenso do grupo, mas ressalva que, na maior parte dos casos, o sentido "is not culture-specific; it is grounded in common human experience". De um lado, tomando o objeto enquanto instrumento, Maquet defende que eles "may be understood independently from their cultural determinations" (um artefato em forma de lâmina com uma empunhadura será uma faca em qualquer cultura) (p.30). De outro, mesmo os simbolismos culturais (a percepção da faca como um símbolo de masculinidade, por exemplo), aparecem como lastreados na "common human experience" (o reconhecimento imediato da forma fálica da faca) (p.31).

Assimilando restritivamente os princípios semiológicos, Maquet delimita a relação codificada entre referente e referido a um universo reduzido, em particular às palavras. Assim, a cultura material participaria em um grau muito pequeno do processo de atribuição artificial, codificada, de valores e sentidos; sua existência poderia ser cultural, mas em uma cultura concebida menos como conjunto distinto de atributos de uma sociedade do que como caráter geral da humanidade.

\section{A cultura e o universo social}

A crítica dos postulados acima tem sido feita com freqüência e competência, o que nos dispensa de uma apreciação mais geral e exaustiva. Apenas conviria salientar alguns pontos de interesse, no intuito de reparar tendências de desistoricização da cultura material.

Na própria coletânea, o texto de Rita P. Wright ("Technological styles: transforming a natural material into a cultural object", p.242-69) fornece algumas sugestões. A autora aponta o predomínio, nos estudos antropológicos, de uma visão em que ". 'things', as objects of study, were viewed exclusively as reflections of underlying mental constructs" (p.243). Em decorrência, as atenções das abordagens, capitaneadas pelo estruturalismo e pela antropologia cognitiva; concentraram-se em desvendar as crenças, os valores e as atitudes de uma cultura. Para Wright, a trajetória da arqueologia vem contribuindo para alargar os horizontes, deslocando o foco das considerações ideológicas, mas sem as perder de vista, para as relações sociais. Do mesmo modo, abordagens alternativas na própria antropologia têm visto a cultura material em um contexto em que se evidenciam fatores como a adaptação ecológica ou a organização política 
(p.244). A contextualização é, aliás, o motor da análise proposta: se existe um contexto conceitual, que remete ao universo mental do criador là manipulação tecnológica de materiais; às escolhas de produçãol, existe igualmente um contexto físico, que se refere a uma nova ordem espacial e temporal em que o objeto se associa a outros objetos e a um mundo social. Centralizar a análise em objetos em movimento em contextos de produção e consumo, mais do que em objetos isolados, permitiria um melhor entendimento da dinâmica social do grupo (p.245 e segs.)

É certo que Wright não se preocupa em pensar diferentemente a natureza da cultura ou de sua relação com a cultura material. No fundo, a autora reforça a dicotomia entre um núcleo originador de realidades e um segmento físico que o reproduz. Todavia, ao introduzir - ao lado dos elementos ideológicos - um ingrediente social, se não afasta de vez, ao menos permite frear a desistoricização. Aqui, a cultura material ainda aparece como um reflexo, mas que agora incorpora também estruturas sociais, além de perspectivas culturais (p.248). Há limites claros: reproduz-se o divórcio que vimos acima entre cultura e cultura material, entre os quais se vislumbra uma "transferência de princípios", que permite explicar porque, digamos, a cerâmica pode refletir a estrutura social de seu contexto de fabricação e uso.

De fato, há um esforço de alguns autores em evitar uma ênfase exclusiva nos componentes simbólicos da cultura. C. C. Lamberg-Karlovsky, em seu artigo "The biography of an object: the intercultural style vessels of the third millennium b.C." (p.270-92), estuda a extensa presença geográfica (Mesopotâmia e lrã) e cronológica (2600-2200 a.C.) de uma categoria de vasos de clorita com motivos incisos. Os significados simbólicos dos desenhos e dos contextos arqueológicos (templários e funerários) permitem, segundo o autor, apontar o compartilhamento intercultural de um sistema de crenças e rituais ligado à morte e às práticas funerárias. No entanto, as questões relativas à produção e distribuição dos vasos não são descartadas: procura-se posicionar o estudo face ao debate acerca da circulação de bens, que opõe aqueles que pensam a distribuição através de mecanismos formais de mercado, oferta e procura e preços e aqueles que defendem a existência de sistemas de alocação variados, assentados em mecanismos de distribuição, reciprocidade ou troca de bens de luxo entre elites. A abordagem simbólica do autor, no entanto, propõe-se superar e reordenar o debate: "Given the specific symbolic significance of this artifact, its distribution need not conform either to formal models of economics or to mechanisms of exchange theory. Behavior dealing with one of the great rites de passage of human existence - specifically, death - suspends the rationality on which theories of market and exchange systems operate" (p.289).

\section{Cultura e comportamento}

Uma das tendências nos estudos norte-americanos de cultura material, decorrente da influência da psicologia behaviorista, é o destaque aos aspectos comportamentais. Em muitos casos, trata-se mesmo de uma definição comportamental da cultura. Em vários dos autores aqui analisados, a cultura material aparece como um fator do comportamento humano ou, ao menos, 
largamente influenciada por ele. Tomemos como exemplo o artigo programático de Michael $O$. Jones, intitulado "Why take a behavioral approach to folk objects?" (p. 182-96).

Antes de mais nada, é preciso notar que uma noção béhaviorista da cultura não se limita à constatação axiomática de que tudo que diz respeito ao humano (inclusive a cultura material) tem sua matriz nos comportamentos. Comportamental é a característica geral de todos os aspectos da cultura, dos materiais aos simbólicos. No texto de Jones, as várias esferas não deixam de aparecer enquanto tais, mas são alinhavadas sob uma abordagem comportamental. Assim, na explicação de traços culturais que se exprimem nos artefatos, além dos aspectos tecnológicos (técnicas; instrumentos; matérias-primas, etc.), das motivações, aspirações e seleções dos produtores e usuários e das imposições de modelos precedentes, seria indispensável, para o autor, uma aproximação que focalizasse as circunstâncias relacionais de materialização do objeto e desse conta dos princípios psicológicos, comunicativos e interacionais do processo (p. 194). A proposta é mais cumulativa do que alternativa: "While we can view the production of objects as a reflection of historical processes, as an element of culture, or as an index of social conditions and processes, we can also investigate some things in their immediate situation of manufacture as aspects or manifestations of human behavior" (p. 194).

Um ponto em comum com abordagens já vistas é a ênfase no indivíduo como plataforma das operações culturais. Embora não se negue que a cultura se defina em um patamar supra-individual (como padrão interpessoal, por exemplo), o foco da atenção repousa nas atitudes individuais. São as escolhas do indivíduo, em um campo de limitações e possibilidades e em interação com outros comportamentos, que revelam a cultura e, por decorrência, se refletem na cultura material. Adequando seus procedimentos de pesquisa a esses pressupostos, Jones analisa a produção de cadeiras de um único artesão de Kentucky no decorrer da década de 60, buscando isolar os fatores explicativos das formas nas circunstâncias comportamentais envolvidas na produção, tornadas acessiveis mais pela observação etnográfica em campo e pela entrevista do que pela análise dos objetos. Este é um risco implicado na abordagem, embora não seja exclusivo dela nem incontornável: inverter os papéis e explicar a cultura material pelo comportamento. É uma inversão recorrente. Por exemplo, no já citado artigo de Prown, alguns objetos (mesas de jogol são efetivamente mobilizados para propor e solucionar questões acerca de alterações comportamentais entre os períodos anterior e posterior à Independência, em 1776 las relações entre gêneros; as idéias acerca da autoridade; os comportamentos privado e corporativo...), porém, permanece a nítida impressão de que um macrofenômeno, a Revolução, subjaz à análise da cultura material, orientando-a, mas não sendo informado por ela.

Cultura e psicologia

Freqüentemente, devido a uma visão compartimentada do fenômeno cultural, categorias diversificadas compõem o conjunto sob a vista do especialista. No artigo de Jones (p.182), são arrolados, lado a lado e sem hierarquização 
visivel, noções relativas ao mundo físico, índices das relações sociais e formas de reprodução e ajuste emocional. Além disso, tais elementos podem articular-se (refletindo na cultura material) em esferas distintas, igualmente não hierarquizadas: - espírito de uma época; as crenças de uma sociedade ou subgrupo; as experiências de um indivíduo. O que ocorre sem que se imponha nenhum esforço de explicação da passagem dos tenômenos de um nível a outro.

A compartimentação da noção de cultura e o acúmulo simplesmente paratático das partes implicam problemas aos quais voltaremos. Por ora, salientemos um único aspecto dessa série de idéias: a premência do sujeito na definição do lugar social da cultura material.

Mihaly Csikszentmihalyi ("Why we need things?", p.20-9) procura estabelecer os aspectos psicológicos das relações entre os homens e as coisas. O eixo de seus argumentos é a dependência psíquica face aos objetos, fruto de uma necessidade de ancoragem da personalidade em bases concretas, físicas: como o humano é, em si, subjetivo, e como a mente é instável, as coisas cumpririam a função de estabilizar o eu (self), conferindothe uma plataforma sólida e objetiva (p.23).

Os modos pelos quais a cultura material participa desse processo de estabilização do eu seriam variados: como dispositivo de demonstração de poder do possuidor, de sua energia erótica vital ou de seu lugar na hierarquia social; como mecanismo que fornece e revela continuidade temporal, evitando a dispersão do eu; enfim, como evidência concreta do lugar do eu numa rede social. Vê-se logo que os encaminhamentos propostos por Csikszentmihalyi aproximam-se mais da psicologia social ou mesmo da sociologia do que de uma psicologia do indivíduo.

Dois desdobramentos desse texto são particularmente úteis. Em primeiro lugar, a formulação dos papéis e dos valores simbólicos da cultura material é mutável no interior de uma mesma sociedade, em função dos subgrupos considerados: homens e mulheres; jovens e velhos etc. (p.26). É uma prevenção importante contra certas generalizações. Segundo, a necessidade le, poderíamos acrescentar, as formas) de uso simbólico dos objetos varia consideravelmente de uma sociedade estável para uma marcada pela mobilidade (p.27). Isto sugere que uma tipologia baseada em critérios gerais (por exemplo, o grau de mediação das relações sociais, distinguindo entre sociedades simples e complexas) poderia orientar (e é esta a função das tipologias) o entendimento do papel da cultura material em geral ou de certas categorias de objetos. Por exemplo, poder-se-ia estabelecer o maior ou menor potencial das vestimentas como sinalizadoras de status em uma sociedade específica, de acordo com sua aproximação de um modelo de comunidades face-to-face ou de grupos altamente mediatizados.

O estabelecimento de gradações no uso de coisas materiais para a projeção do eu não teria interesse exclusivamente para o estudo dos aspectos simbólicos do processo de formação histórica do indivíduo, senão também abriria uma perspectiva interessante de análise de problemas sócio-econômicos, como sugere a observação de Csikszentmihalyi de que, na sociedade norte-americana, a exarcebação desses procedimentos teria conotações negativas e perigosas por acirrar a disputa por bens materiais e incentivar o uso desenfreado dos recursos 
(p.28). Acrescentemos que, nessa linha, todo um estudo da obtenção de matérias-primas, da circulação de bens, dos sistemas de propriedade, dos processos de dispêndio e acúmulo etc. etc. poderia ser feito sob a ótica das relações entre sociedade e cultura material, intermediadas pelas necessidades psicológicas e simbólicas. O programa de Csikszentmihalyi embute, no fundo, uma sugestão de mudança comportamental: uma reeducação na relação com o mundo material, através da internalização de controles psíquicos, visando liqüidar ou atenuar a dependência emocional face às coisas físicas; o que implicaria em valorizar os objetos como instrumentos mais do que como projeção de nós mesmos. Mas isso não seria uma aposta numa improvável erradicação do simbolismo da cultura material? Num universo físico semanticamente asséptico?

O objeto pelo objeto

Até aqui, vimos noções de cultura que circunscrevem e potencializam alguns elementos ou niveis (mente; relações sociais; comportamento; psicologia), bem como suas implicações para a equação cultura/cultura material. Trataremos, por último, de um caso revelador.

Talvez seja justamente na área de estudos da cultura material que se verifiquem os maiores impulsos a reconhecer nos objetos qualidades imanentes, que eles, efetivamente, não podem ter. Estamos face ao que se tem chamado, genericamente, de fetichismo. Sua característica é a transferência aos objetos lque, por definição, possuem apenas propriedades físico-químicas) de qualidades do universo orgânico (quer biológico, quer social).

Mesmo quando não se chega a tanto, certas posições inspiram cuidados. Alguns autores chamam a atenção para as imposições que um universo já estabelecido de objetos (ou partes dele) exerce nas "gerações" posteriores. É o caso, por exemplo, das tradições estilisticas, que condicionam a escolha do tipo de matéria-prima a ser usada, como demonstra Robert Friedel em seu artigo "Some matters of substance" Ip.4150). Em tais casos, não seria preciso - nem mesmo correto - negar a influência em si, mas seria enriquecedor explicitar (o que nem sempre se faz) que a operação não se dá aułonomamente, do mundo físico para o mundo físico, mas por intermediação cultural lé aí que se estabelecem, entre outras coisas, as tradições). O que significaria tornar a própria influência um processo cultural, passível, pois, de especulação histórica.

Em seu artigo sobre a notável permanência, por mais de 3000 anos, da forma e decoração dos vasos ding chineses, Jessica Rawson ("The ancestry of chinese bronze vessels", p. 51-63) delimita as razões da sua reprodução contínua, concluindo que apenas o acúmulo de novos valores e funçōes a explicaria. Ora, valores e funções são atribuídos socialmente e sua variação em uma mesma forma fisica apenas confirma que não existe imanência.

Outros autores, porém, pensam de modo diferente, conferindo ao mundo dos objetos a ação que subtraem ao universo social: "In some respects artifacts are like new species that reproduce themselves alongside biological ones (..). We like to think that because objects are human-made they must be under our control. However, this is not necessarily the case. An object with a specific form and function inevitably suggests the next incarnation of that object, which then almost certainly will come about" (Csikszentmihalyi: p.21). 
No limite, o fetichismo lembra a imagem de uma terrivel ficção cientifica em que imperam objetos orgânicos, autômatos. Nesse estágio, a cultura material seria o reflexo ou a herdeira de si mesma. E a sua única explicação estaria em uma cultura que só não seria a pura materialidade porque, agora, o material estaria, ele próprio, dotado de vida. $O$ único antídoto seria repetir a máxima dos estudos de cultura material: o que importa não é o objeto, mas as relações sociais.

\section{Cultura e cultura material}

Não se trata de tentar, aqui, um conceito definitivo de cultura. Mas convém apresentar algumas considerações que permitam superar os obstáculos identificados acima e, sobretudo, tornar operacional a noção de cultura material.

Grande parte daqueles problemas advém de uma visão compartimentada da realidade cultural, que, não por acaso, já se apresentava entre os folcloristas e antropólogos norte-americanos da primeira metade do século. Concebeuse a cultura como a somatória de componentes discretas (ideológica; sociológica; material) distribuídas estratigraficamente. É tal visão que permitiu a diferenciação entre niveis materiais e imateriais da cultura. Desse modo, a componente ideológica, por exemplo, fundava-se na imaterialidade do pensamento, do conceito, cujo suporte, de resto, seria a palavra, oral ou escrita. Isto induzia a associar, erroneamente, o pensamento à palavra. Por vezes, a decorrência analítica foi a impossibilidade de apreender a ideologia senão através das manifestações verbais.

Romper essa perspectiva segmentária permitiria ver como o ideológico pode expressar-se, igualmente, no universo físico. $O$ imaterial, na cultura, não corresponde a um nivel prisioneiro do concreto, cuja localização espacial seja possivel. A sua identificação, portanto, apenas pode ser o resultado de um ângulo de visão do observador, impossibilitado de abarcar o todo. Seguindo o mesmo raciocínio, não se poderia falar dos aspectos materiais da cultura lou da cultura material) sem falar simultaneamente da imaterialidade que thes confere existência (sistemas classificatórios; organização simbólica; relações sociais; conflitos de interesse, etc.).

Seria mais conveniente falar em funções do que em níveis, evitando uma visão estanque da cultura e permitindo vêta como um sistema de componentes intercambiáveis, cujas articulação e dinâmica não estariam limitadas por posições fixas. A cultura material é material pela sua "fisicidade" (esta sim imanente), mas não por estar presa a pretensos níveis materiais da vida social. No jogo social, a sua função depende de configurações mutáveis, que não estabelecem fronteiras prévias entre as várias dimensões culturais.

É interessante notar que, de modo similar, no âmbito da própria historiografia, tem-se superado, por influência da sociologia e da antropologia, a separação entre práticas e representações em benefício de uma dialética mais complexa da ação social. Prática e representação são tomadas como dimensões inextricáveis da vida cultural, alimentando-se mutuamente, sem que as seja possível compartimentar. Uma conseqüência positiva é que se oblitera, assim, a criação de nexos causais lineares. 
Nesse quadro, a materialidade é um atributo inerente, mas que, porém, não esgota o objeto culturalmente considerado. Do contrário, tomado por suas características físicas, o objeto informaria apenas sobre a sua própria materialidade. Logicamente, mesmo as características físicas são resultado de um processo social que atua desde a seleção da matéria-prima, como lembra $R$. Friedel (p.46): vários motivos interferem na escolha (funcionalidade; adequação; economia; estilo; tradição/familiaridade), variando de acordo com as circunstâncias (geográficas; técnicas; da moda; de competição). Assim como em relação aos objetos, os significados das matérias-primas são estipulados culturalmente e podem afetar o sentido das coisas que compõem, sem, porém, thes corresponder totalmente.

$\hat{E}$ justamente por não se limitarem aos seus ingredientes materiais que as coisas têm um papel que excede ao de quadro físico da vida social. Tal distinção seria, aliás, inconcebível. $\bigcirc$ universo material não se situa fora do fenômeno social, emoldurando-o, sustentando-o. Ao contrário, faz parte dele, como uma de suas dimensões e compartilhando de sua natureza, tal como as idéias, as relaçōes sociais, as instituições.

Eis ai a fortuna do termo cultura material, além das ambigüidades possiveis: ele denota que a matéria tem matriz cultural e, inversamente, que a cultura possui uma dimensão material.

Em suma, como a cultura não é um segmento do fenômeno social, mas uma dimensão extensiva sua, não se poderia isolar uma seção que não fosse cultural ou uma outra que o fosse exclusivamente. Desse modo, a questão da cultura não pode ser dissociada daquela da materialidade, sob o risco de The conferir um caráter fantasmático. Bastaria dizer que não existem sentidos, valores ou mensagens culturais que sejam completamente internalizados na consciência (individual ou coletiva), que sejam criados em uma marriz que dispense a materialidade ou que sejam vetorizados apenas por circuitos operacionais imateriais. A cultura material é, por excelência, matriz e mediadora de relações.

\section{A cultura material como documento histórico}

Na introdução à coletânea, Steven Lubar e W. David Kingery (p.VII$\mathrm{XVIII} \mathrm{admitem} \mathrm{a} \mathrm{escassez} \mathrm{de} \mathrm{tentativas} \mathrm{de} \mathrm{mobilização} \mathrm{das} \mathrm{coisas} \mathrm{materiais} \mathrm{para}$ a compreensão das sociedades. Salientam que, ao menos em parte, as dificuldades advêm do hábito arraigado de ler somente os escritos e de ouvir apenas os pronunciamentos do passado. De fato, em geral, as resistências ao uso da cultura material estão associadas ao predomínio do documento escrito. Normalmente, a cultura material é esvaziada de seu potencial explicativo da experiência humana, restando como fenômeno a ser elucidado a partir de outros referenciais. Outras vezes, é apenas a aproximação com o texto ou seu enquadramento aos métodos da leitura textual que qualificam seu uso.

Embora Lubar e Kingery reafirmem o potencial da cultura material, o estágio atual ainda é de superação das dúvidas e oposições, fazendo com que a afirmação da cultura material como documento tenha grande destaque na reflexão. 
Negação, resistência, hierarquia

É interessante notar que mesmo os estudiosos da cultura material levantam restrições sérias. Alguns exemplos, presentes na coletânea em foco, ilustram as mais comuns:

- No artigo já citado, J. Maquet aponta o caráter mais indicativo do que conclusivo das inferências a partir da cultura material, reconhecendo-thes resultados mais prováveis do que necessários e, além disso, dependentes de confirmação por fontes escritas.

- Robert B. Gordon ("The interpretation of artifacts in the history of technology", p.74-931, repetindo idéia corrente, defende que a importância da cultura material cresce na medida em que faltam documentos escritos. Tal visão atrela o potencial de uma fonte à debilidade de outra e sugere que, na abundância de registros escritos, a cultura material seria dispensável, como se houvesse um rol fechado de indagações que pudesse ser respondido por um conjunto ideal de fontes. Algumas colocações bem intencionadas acabam por reforçar a idéia: R. P. Wright (p.244 e segs.) sugere que é a ausência de documentos escritos que qualifica o trabalho de tipo arqueológico.

- Por vezes, há uma enorme relutância em raciocinar exclusivamente a partir da cultura material. É o caso do artigo de Robert W. Bagley ("Replication techniques in eastern Zhou bronze casting", p.231-41). Através de análises de padrões tecnológicos e formais, o autor estabelece informações consistentes acerca do processo de produção dos vasos de bronze hu chineses, durante o século V a.C. (por exemplo, a composição fragmentada do molde cerâmico, que exigia alta especialização do ceramistal, que permitem inferências sobre a existência de um sistema fabril complexo, assentado em grande divisão técnica do trabalho e em sua articulação centralizada, afastando a hipótese de pequenas oficinas de artesãos independentes. Não obstante, para corroborar a sua argumentação, como um finis coronat opus, Bagley apresenta uma inscrição feita em uma taça de vinho, datada de... meio milênio mais tarde!

De um modo geral, as reservas dizem respeito ao alcance e à confiabilidade da cultura material, apresentada, então, como um documento de segunda categoria, incompleto e limitado, quando comparado à fonte escrita. No fundo, nota-se um descompasso ainda enorme entre os padrões estabelecidos de validação do conhecimento histórico e o valor probatório reconhecido às fontes materiais.

Mesmo a boa vontade em revelar aspectos positivos da cultura material, por vezes tropeça em equívocos. Para J. D. Prown (p. 17), os artefatos permitem um contato direto com a cultura estudada, sem a intermediação do entendimento do observador. Tratar-se-ia, segundo o autor, de um contato afetivo com outras experiências sensoriais, proporcionado pelo compartilhamento de bases neuropsicológicas comuns a todos os seres humanos. Ao menos dois problemas devem ser mencionados neste caso. Primeiro, ainda que não se deva absolutamente negar que os atributos físicos do objeto atuem sensorialmente no processo de análise (como, de resto, que sejam fatores fundamentais na exposição museográfical, eles não substituem a percepção intelectual. $\bigcirc$ contato sensorial não elimina a intermediação dos nossos pressupostos mentais. Em outras 
palavras, as questões colocadas pelos objetos não são mais autênticas - como quer Prown (p.13) - por surgirem de sua evidência primária, diminuindo as imposições do investigador. Segundo, a percepção humana não se esgota em suas bases biológicas ou psíquicas: ao contrário, é culturalmente determinada e historicamente mutável, como têm demonstrado diversos estudos. Isso significa que a apreciação, mesmo sensorial, dos elementos físicos não dispensa a análise cultural e histórica. O próprio Prown admite o condicionamento cultural, mas, como vimos, sua idéia de cultura é por demais dilatada, inespecífica; sua ênfase, de qualquer modo, está na experiência humana comum.

O objeto como documento

É uma ilusão pensar que um objeto incorpora seus atributos morfológicos, fisiológicos e semânticos em um único ato criador e os mantém por toda sua trajetória. Embora em nenhum aspecto haja um tal congelamento, alguns são mais visiveis que outros. Quanto à forma, será fácil perceber as alterações, seja se se possui uma idéia exata do estado original, seja por intermédio de análises laboratoriais, que revelarão acréscimos, subtrações, substituições etc. etc. As alterações na função também são, em geral, facilmente perceptíveis. As transformações nos significados, por serem mais abstratas làs vezes, imperceptíveis na materialidadel, exigem esforço maior de compreensão por parte do historiador (mesmo que a apreensão pelos agentes seja imediata). A trajetória dos objetos altera-se em função quer das transformações da sua própria natureza física quer da sua inserção social (processos de desgaste, manutenção, reciclagem). Normalmente, as alterações estão articuladas, envolvendo transformações nas três dimensões, embora possa haver mudança semântica sem intervenção na forma, e assim por diante.

Duas implicações impõem-se ao historiador.

Em primeiro lugar, face a uma trajetória em que o próprio objeto perde e incorpora atributos, em que atravessa redes de significados que o classificam e reclassificam em categorias constituídas culturalmente, não se trata mais de desvendar características perenes, mas de identificar as alterações e explicar suas razões. Pela sua própria materialidade, os objetos perpassam contextos culturais diversos e sucessivos, sofrendo reinserções que alteram sua biografia e fazem deles uma rica fonte de informação sobre a dinâmica da sociedade (transformações nos modos de relacionamento com o universo físico; mudanças nos sistemas de valores etc.). É preciso investir no entendimento dessa cadeia mutável para incorporar a cultura material em sua plenitude documental. Ao invés de lamentar a perda de supostos traços originais, é de se fazer dela objeto de estudo: por que uma sociedade opera transformações nas formas, funções e sentidos da cultura material? Evidentemente, tal indagação complica imensamente vários fatores envolvidos no trabalho, por exemplo, a noção de contexto, como veremos adiante. Mas os ganhos seriam compensadores.

Entretanto, este é o segundo ponto, a noção de trajetória não se deve limitar à vida do objeto enquanto tal: deve estender-se para além daquele momento em que o objeto transforma-se em documento, ou seja, para o interior da operação intelectual que o retira (abstrata, mas nem sempre fisicamente) do 
seu contexto original (aquele em que foi produzido, consumido, reciclado, descartado etc. etc.) e o insere na nova situação, em que se torna, prioritariamente, base de informações. É desnecessário dizer que essa operação somente existe por intervenção do observador. Mas o que nos interessa é chamar a atenção para o fato de que, também nessa fase documental, a cultura material ganha atributos inéditos, em um processo de interação com o historiador.

Assim, o trabalho com a cultura material não exige apenas disposição de alargar o espectro documental; implica também uma mudança de raciocínio, que habilite a pensar outros problemas ou os mesmos problemas de outra forma. Muitos dos impasses a que referimos advêm da imposição de indagações inadequadas à cultura material, condenando-a preliminarmente à baixa performance ou à completa inutilidade. Se, de um lado, a cultura material, por si, já permite propor a análise de fenômenos não acessiveis por fontes escritas, de outro, impõe reorientações e afinamentos metodológicos, não sendo possivel uma simples transferência dos procedimentos heurísticos comuns na pesquisa textual, como nota em seu artigo lan W. Brown ("The New England cemitery as a cultural landscape", p. 140-59).

Uma solução consistente ao problema da inserção da cultura material no processo de produção do conhecimento histórico não poderá partir, no entanto, da defesa de sua superioridade ou da exclusão dos documentos escritos. Ao contrário, tem-se apontado para uma perspectiva de combinação, que excede à simples sobreposição de informações provenientes dos dois campos de análise e induz à sua interação mútua e controle recíproco. Um exemplo é o interessante artigo "Gardens and society in eighteenth-century England" (p.94-1 14), em que Thomas Williamson constata a insuficiencia de uma abordagem tradicional que buscava estabelecer uma seqüência linear nos estilos dos jardins ingleses do século XVIII, explicando-a em função dos debates estéticos ou filosóficos correntes na alta cultura. Para o autor, os problemas nessa visão seriam muitos: desde a falta de resposta para as mudanças de estilo e para a sua difusão popular até a atribuição de poderes causais a discursos que poderiam ser, na verdade, racionalizações posteriores dos desenhos dos jardins. Para avançar na análise, Williamson propõe concentrar-se nos próprios artefatos, em seu contexto social, econômico e topográfico a partir das evidências arqueológicas, mas também iconográficas, cartográficas e textuais (em particular as não-eruditas). Um arranjo calibrado de fontes permite, então, entender melhor as relações entre os jardins e a sociedade, como também (poderíamos acrescentar) as próprias formulações presentes nas fontes literárias eruditas, agora vistas como um fator a ser avaliado conjuntamente com outros e não como explicação universal.

Outros salientam o potencial da cultura material para propor questōes e encaminhar respostas que não surgem da documentação escrita, embora descartem a oposição em benefício do paralelismo entre os dois tipos de fonte. Em seu artigo "Artifacts as expressions of society and culture: subversive genealogy and value of history" (p. 160-81), Mark P. Leone e Barbara J. Little mobilizam duas séries independentes de artefatos para a compreensão de uma mesma visão de mundo, emergente no período subseqüente à Independência norte-americana. A primeira série é formada pelo Palácio do Governo de Annapolis, em Maryland, e por sua vizinhança, redesenhados na década de 80 
do século XVIII: o domo panóptico do edifício e sua localização no ponto mais alto e visível da cidade, articulando a rede de ruas, mostram, para os autores, uma resposta à teoria do individualismo vitoriosa na Declaração de Direitos, sinalizando a emergência do novo Estado regulador com seus mecanismos de vigia e de indução de comportamentos. A segunda série compõe-se de três quadros de Charles Willson Peale, importante retratista do período Federal e fundador do primeiro museu de História Natural da nova nação, na Philadelphia. As telas em questão estão intimamente ligadas à sua atividade museográfica e têm ai as bases para seu entendimento: Peale faz do museu um modelo, que assimila as regras do mundo e as expõe didaticamente ao cidadão da recém-fundada república, fornecendo os parâmetros para situar a natureza (pedras, insetos, pássaros, mas também os nativos americanos) e o passado nacional (incluindo seus heróis). Como em relação ao palácio do Governo de Annapolis, a questão central é a da internalização dos valores de uma ideologia americana em formação.

Artefatos, estruturas, paisagens culturais

Fala-se corriqueiramente de objetos ou artefatos, mas a cultura material tem uma dimensão mais ampla e diversificada, envolvendo todo o segmento físico socialmente integrado. Embora as consideraçōes feitas sobre cada unidade isoladamente sejam, a princípio, extensivas a conjuntos, a complexidade e a amplitude exigem reflexões específicas: a lógica da composição não é dada pela somatória das lógicas das suas partes.

Do mesmo modo que, na arqueologia, a noção de documento incorporou, além de objetos individualizados, estruturas, arranjos, contextos espaciais etc. etc., também nos estudos de cultura material a tendência foi a inclusão de bases heurísticas cada vez mais abrangentes. Um dos primeiros impulsos foi, sem dúvida, a necessidade de formulação de séries, quer as homogêneas (de um mesmo tipo de artefato: por exemplo, cerâmica, associada ao esforço de datação e elucidação de processos de difusãol, quer as séries heterogêneas (objetos diferentes ligados funcionalmente: por exemplo, de caça ou de cozimentol, quer, ainda, arranjos que procuravam cobrir a totalidade material de uma unidade de pesquisa (todos os artefatos domésticos, por exemplo). Logo, as preocupações estenderam-se a articulações mais vastas: cemitérios; portos; fábricas; quarteirões; cidades inteiras. Vejamos alguns exemplos.

Steven Lubar ("Machine politics: the political construction of technological artifacts", p. 197-214) procura definir a especificidade das máquinas no conjunto da cultura material: como todos os outros artefatos servem de intermediários de nossa relação com o mundo; são, como eles, agentes ativos que contribuem para definir nosso lugar na natureza e nas relações sociais; mas têm, em geral, maior potencial inovador, redefinidor e criador de novas relações, apenas parcialmente baseadas nas velhas (p. 198). Não se trata, entretanto, apenas de um fator de propensão exclusivamente tecnológico: a tecnologia é definida claramente como fenômeno cultural, como incorporação física da ordem social. Desse modó, a mobilização das máquinas como documentos não estará limitada à análise dos fatores técnicos da produção; ao contrário, levará a uma 
abordagem necessariamente sociocultural. Lubar fornece um exemplo das imbricações entre tecnologia, política e mentalidade: em meados do século passado, as máquinas a vapor instaladas em Charleston, na Carolina do Sul, foram projetadas para incorporar traços do revival helênico, então em moda na arquitetura; com isso, procurava-se associar os valores republicanos ao desenho das máquinas e permitir sua adoção em uma região tradicionalmente refratária à industrialização (p.200).

Procura-se, assim, superar o atrelamento entre os estudos do maquinário e uma história estritamente tecnológica, ou mesmo econômica. Lubar chama a atenção especialmente para os aspectos políticos envolvidos na constituição da cultura material de caráter tecnológico: "Machines are the material culture of politics in its broadest sense: politics as the interactions between groups of people. I shall call this 'machine politics': the ways in which machines modulate, influence, and intermediate the interactions of groups" (p. 198).

De modo semelhante, W. David Kingery ("Technological systems and some implications with regard to continuity and change", p.215-30/ focaliza os fatores sociais, ideológicos e estéticos de mudança e continuidade do sistema tecnológico da cerâmica renascentista italiana (p.218). Kingery explora as articulações entre as alterações tecnológicas que levaram ao desenvolvimento da cerâmica maiólica na Itália central e setentrional durante o último quartel do século XV (precursora da faiança européia), o novo repertório de cenas narrativas e históricas (istoriato) usado em sua decoração e, finalmente, o processo de substituição da aristocracia feudal por uma elite urbana: a consolidação de um novo tipo de riqueza, comercial e bancária, os novos padrões de comportamento social e, em particular, de consumo e exposição pública estão na raiz das inovações tecnológicas. O que se busca é interpretar de um modo adequado as etapas de produção e uso do objeto em seu contexto: "Design, manufacture, distribution, and use are all activities involving cultural constraints and social organization. (..) The effects of technology on culture and the influence of culture on technology are multidimensional. An internalist approach looking toward technology as applied science with a product as the final output is simply wrong" (227).

Uma estrutura espacial complexa, que tem atraído a atenção dos estudiosos nas últimas décadas é o cemitério. Há algum tempo, a distribuição dos túmulos, as esculturas, as inscrições epigráficas, a iconografia vinham se tornando objeto de pesquisa, embora isoladamente, visando fornecer informações sobre zonas específicas de interesse: genealogias familiares; práticas de segregação étnica; hierarquias sociais; ideologia funerária etc. A partir da década de 60 , porém, no âmbito da arqueologia histórica, uma perspectiva mais integrada procurava, a um só tempo, estabelecer o cemitério como uma unidade de pesquisa e inserito em uma paisagem cultural mais vasta.

Uma decorrência dessa perspectiva integrada é a ênfase na contextualização. Esta é a preocupação central do artigo de I.W.Brown na coletânea: "Changes in society certainly do leave an imprint on the objects in use, but to understand what the imprints signify we must be able to control time and space. Context is indeed the key to understanding what material culture can tell us about historical processes" (p. 144). Especificamente em relação ao cemitério, 
Brown nota a relativa facilidade em controlar os três fałores fundamentais: tempo, espaço e forma (p. 145). Talvez não seja tão simples. Todavia, duas considerações deveriam ser feitas pelo historiador. Em primeiro lugar, deve-se enfatizar a consciência cada vez maior da importância da constituição de séries: o artefato - ainda que, por vezes, conserve individualmente algum potencial heurístico - ganha sentido no interior de seqüências constituidas pelo interesse da pesquisa, de acordo com critérios variados de articulação: cronologia, morfologia, fisiologia, matéria-prima, tratamento de superfície etc. A segunda observação diz respeito à própria noção de contexto, inserida agora em uma complexidade inédita; vale aqui o que foi dito sobre a biografia do objeto: configurações cambiantes da trajetória das estruturas transformam-se em foco da pesquisa. Deixa-se de priorizar um contexto original em benefício da sucessão de contextos, buscando-se controlar intelectualmente cada passo da dimensão diacrônica.

Um dos elementos centrais dessa complexidade está justamente no fato de que certas unidades físicas da pesquisa têm uma trajetória bem diferente daquela do sítio arqueológico tradicional. Costumeiramente, este foi caracterizado, em alguma medida, por um grau de congelamento do seu estado. Muitos dos esforços dos arqueólogos buscaram estabelecerer as tendências gerais de formação do depósito, seus agentes físico-químicos e culturais. Embora a idéia de uma situação ideal estática seja problemática em todos os segmentos da arqueologia, em alguns deles a questão ganha peso particular: é o caso da arqueologia histórica de períodos recentes, em que o sítio arqueológico pode estar sob plena ocupação humana. Por outro lado, o conjunto de referências contexłuais com as quais o pesquisador trabalha também é totalmente diferente daquele relativo ao objeto museológico: fora da escavação ou do museu, os objetos e as estruturas materiais exigem tratamentos que assimilem, entre outras coisas, as especificidades da sua inserção na vida social de comunidades atuais.

Poderíamos dizer mesmo que se alteraram as próprias relações espaciais e temporais do sistema documental, impondo a necessidade de reflexões não previstas anteriormente. A mudança do campo heurístico não pode ser resumida, pois, a um alargamento quantitativo: implica formas de pensar conexões que não se colocavam quando o objeto era considerado individualmente e, além disso, faz das próprias conexões o dado a ser considerado, mais do que o objeto.

É no campo do estudo da paisagem culłural que essas questões assumem maior relevo. O artigo de Peirce Lewis ("Common landscapes as historic documents", p. 115-39), no entanto, está longe de ser suficiente para a consideração dos problemas. De um lado, o autor assinala, corretamente, a necessidade de compreensão da paisagem como uma construção cultural, prevenindo contra sua naturalização pelo observador: "Human landscapes differ in appearance from place to place for the self-evident reason that all cultures have certain collective ambitions about the way the world should operate and because they possess peculiar means of achieving those goals of profit, pleasure, and safery. Simply because cultures are peculiar, their landscapes are peculiar too. And, of course, because cultures change through time, their landscapes also change" (p.116) De outro lado, porém, as premissas metodológicas não vão 
além de apontar a possibilidade de uma leitura análoga à que se procede com um documento escrito, considerando a paisagem como um gigante palimpsesto com camadas sobrepostas de "literariedade", freqüentemente apagadas e emendadas pela ação humana.

Balanço e perspectivas

Na introdução à coletânea, Steven Lubar e W. David Kingery manifestam a intenção de superar fronteiras e descobrir bases comuns entre as áreas e os autores envolvidos na interpretação da cultura material. A leitura do volume, no entanto, gera mais preocupações do que esperanças a esse respeito. Os artigos, em sua maioria, mantêm-se atrelados a campos e interesses particulares. Mesmo algumas tentativas de interdisciplinariedade demonstram mais sobreposição do que efetiva articulação.

Em especial, a compartimentação é responsável por perdurarem noções de cultura que não oferecem um lugar adequado à cultura material. A dificuldade em reconhecer a cultura material como matriz e vetor de relações redunda em uma subavaliação de seu papel social e, conseqüentemente, contribui para a formulação de noções de cultura incapazes de assimilátla na extensão de seus significados. Quer a cultura material seja vista como reflexo condicionado do pensamento ou do comportamento humanos, quer como geradora espontânea de novas realidades físicas, seu entendimento como fenômeno social fica seriamente prejudicado.

Uma manifestação desse problema é a concentração, por parte de muitos autores, na produção, mas apenas uma fraca atenção à distribuição e uma total marginalização do consumo. Não se trata apenas da impossibilidade de apreender um ciclo completo do objeto, mas de menosprezar setores em que a cultura material dificilmente seria explicada apenas ou predominantemente por fatores tecnológicos ou econômicos.

A primeira tarefa, que ainda persiste portanto, é a inserção apropriada da cultura material em uma concepção sobre o social, em uma noção de cultura. A obra indica alguns caminhos, mas que parecem insuficientes.

De outro lado, a preocupação metodológica central para o historiador - a inserção documental da cultura material no processo de produção do conhecimento -, embora mereça uma atenção contínua, não é satisfatoriamente resolvida. Também aqui há apontamentos consistentes la ênfase na contextualização, por exemplo), mas dificilmente se superam a dicolomia entre as fontes materiais e escritas ou a diluição das primeiras em métodos de análise concebidos para as últimas.

Não se poderia dissociar esses impasses daqueles gerados pelo posicionamento equivocado da cultura material face à noção de cultura. Neste ponto, a fragilidade diz respeito à própria intenção de se fazer uma História a partir das coisas. O projeto exigiria, forçosamente, uma consideração histórica da cultura material (de seu lugar na estrutura do social e, especialmente, de seu comportamento nos processos de mudançal e um esforço de tratamento heurístico. Quanto ao último problema, há uma tensão clara entre aqueles autores que procuram resolvêto pela assimilação aos métodos de análise textual e os que, 
apontando a peculiaridade da fonte material, propõem procedimentos específicos.

Por fim, é preciso dizer que, se a História - enquanto disciplina privilegiada para o estudo da mudança social - pode contribuir significativamente para o enquadramento da cultura material na experiência humana, por outro ado, não parece estar especialmente habilitada a fornecer instrumentos para operar sua manipulação documental. Como mostram os sucessos e as fraquezas dessa coletânea, a interdisciplinariedade, mais do que uma concessão ou um requinte, é uma absoluta necessidade no campo ainda pouco consistente dos estudos da cultura material. 
Ramos de Azevedo's São Paulo: from the colonial city to the romantic city

Janice Theodoro

The A. analyses through the activity of Ramos de Azevedo the implicit links between São Paulo's colonial past and the Modernist Movement, and the role played by the European "imaginaire" in America, as well as the tecno-scientific traditions with wich he was affiliated.

UNITERMS: Urban History. History of Architecture. São Paulo. Ramos de Azevedo.

Anais Museu Paulista, N. Sér. v.4, p.201-8, jan./dez.1996

O Brasil vai a Paris em 1889: um lugar na Exposição Universal

Heloisa Barbuy

A A. estuda, de um ponto de vista museográfico, o significado da presença brasileira na Exposição Universal de Paris, de 1889. Com base em documentação rica e em grande parte ignorada ou pouco explorada, revela esforços empreendidos para apresentar o Brasil como um país atraente para estrangeiros e analisa o repertório alegórico mobilizado, juntamente com a retórica de diferentes tipos de exposições, sejam de produtos naturais, manufaturados, científicos ou artísticos. UNITERMOS: Exposição internacional. História das exposiçōes, século XIX. Museografia, século XIX. Exposição Universal, Paris, 1889: presença brasileira.

Anais do Museu Paulista, N.Sér. v.4, p.211-61, jan./dez.1996

Brazil goes to Paris in 1889: a place at the Universal Exposition

Heloisa Barbuy

The A. studies the meaning of Brazilian presence in the 1889 Universal Exposition in Paris from a museographical point of view. Based on rich and in large part ignored or underexplored sources, she reveals the efforts made to show Brazil as an attractive country for foreigners and analyzes the allegorical repertoire put into action, along with the rhetorics or different sorts of exhibition, either of natural and manufactured items as well as artistic and scientific in character.

UNITERMS: International exhibition. History of exhibitions, 19th-century. Museography, 19th-century. The Universal Exposition,

Paris, 1889: Brazilian presence.

Anais do Museu Paulista, N.Sér. v.4, p.211-61, jan./dez.1996

História a partir das coisas: tendências recentes nos estudos de cultura material

\section{Marcelo Rede}

Este artigo avalia as idéias de uma publicação coletiva organizada por Lubar e Kingery, History from things. Essays on material culture. Dois problemas são salientados: a formulação de um conceito de cultura que possa abranger os segmentos socialmente apropriados do universo físico e o tratamento metodológico da cultura material como documento histórico.

UNITERMOS: Cultura Material. História e Cultura Material.

Anais do Museu Paılista, N.Sér. v.4, p.265-82, jan./dez.1996

History from things: recent trends in the study of material culture

\section{Marcelo Rede}

This article aims to appraise the ideas of a collective publication edited by Lubar and Kingery, History from things. Essays on material culture. Two problems are put forward: the formulation of a concept of culture that might encompass the socially appropriated segments of the physical universe and the methodological treatments of material culture as historical document.

UNITERMS: Material Culture. History and Material Culture.

Anais do Museu Paulista, N.Sér. v.4, p.265-82, jan./dez.1996 